\title{
Enhanced photocatalytic activity of metal oxides/ $\beta$-cyclodextrin nanocomposites for decoloration of Rhodamine $B$ dye under solar light irradiation
}

\author{
Subramanian Rajalakshmi • Sakthivel Pitchaimuthu • \\ Nagarathinam Kannan • Ponnusamy Velusamy
}

Received: 10 May 2013/ Accepted: 11 July 2014/Published online: 29 August 2014

(C) The Author(s) 2014. This article is published with open access at Springerlink.com

\begin{abstract}
We present the photocatalytic decoloration of Rhodamine $\mathrm{B}(\mathrm{RhB})$ dye with the nanocomposites such as $\mathrm{TiO}_{2}, \mathrm{ZnO}, \mathrm{TiO}_{2} / \beta$-cyclodextrin $(\beta-\mathrm{CD})$ and $\mathrm{ZnO} / \beta-\mathrm{CD}$. Band gap energy of nanocomposites was calculated by UVDRS analysis and the results showed that the band gap energy of $\mathrm{ZnO} / \beta-\mathrm{CD}$ nanocomposite is lower than that of other catalysts. The microstructures of the nanocomposites have been characterized by PXRD and FE-SEM analyses. The results showed that crystallinity and surface morphology of metal oxides (MO) (say, $\mathrm{TiO}_{2}$ and $\mathrm{ZnO}$ ) are not changed in $\mathrm{MO} / \beta-\mathrm{CD}$ nanocomposite systems. GC-MS results showed that the photocatalytic decoloration of $\mathrm{RhB}$ follows the steps such as $N$-deethylation, cleavage of chromophore and mineralization of dye.
\end{abstract}

Keywords $\mathrm{RhB} \cdot \mathrm{TiO}_{2} \cdot \mathrm{ZnO} \cdot \mathrm{TiO}_{2} / \beta-\mathrm{CD} \cdot \mathrm{ZnO} / \beta-\mathrm{CD}$

\section{Introduction}

Rhodamine $\mathrm{B}(\mathrm{RhB})$ is a highly water soluble, basic red dye of xanthene class. It is found as a reddish violet powder and comes under the trade name of $\mathrm{D}$ and $\mathrm{C}$ red no. 19 (molecular formula $=\mathrm{C}_{28} \mathrm{H}_{31} \mathrm{ClN}_{2} \mathrm{O}_{3} ; \quad$ molecular weight $=479.02$ ). It is widely used as a colorant in textiles and food stuffs. It is also a well-known water tracer fluorescent. It causes irritation to skin, eyes and respiratory tract. The carcinogenicity, reproductive and developmental

S. Rajalakshmi - S. Pitchaimuthu - N. Kannan · P. Velusamy $(\bowtie)$

Centre for Research and Post-Graduate Studies in Chemistry, Ayya Nadar Janaki Ammal College, Sivakasi 626 124, Tamilnadu, India

e-mail: velusamyanjac@rediffmail.com toxicity, neurotoxicity and chronic toxicity towards humans and animals have been experimentally proven (Jain et al. 2007; Kelesoglu et al. 2012; Dlamini et al. 2011).

The traditional ways of processing wastewater containing dyes through coagulation-flocculation or adsorption by activated carbon are inefficient since they just transfer the dye molecules from liquid to solid. In the past few years, photocatalysis using semiconductor has attracted more as a new and efficient method to treat wastewater containing colorants. It is well documented that $\mathrm{TiO}_{2}$ and $\mathrm{ZnO}$ can only absorb a small fraction of sunlight (ultraviolet and near ultraviolet) due to their broad band gap (3.0-3.2 eV) and therefore, it is necessary to modify photocatalysts which can effectively be utilized the solar energy to a greater extent (Kou et al. 2012; Beltran-Heredia et al. 2011).

Cyclodextrins (CDs) are cyclic oligosaccharides composed of 6, 7 and 8 D-glucopyranose rings termed $\alpha-, \beta$ and $\gamma-\mathrm{CD}$, respectively. $\mathrm{CDs}$ are shaped like truncated cones, with a hydrophobic cavity and a hydrophilic exterior. The precise number of hydroxyl groups according to the number of glucose units makes it possible to establish strong interactions with other molecules and can form inclusion complexes with guest molecules (Serra-Gomez et al. 2012; Xin et al. 2012). As for the application of CD in environmental chemistry is concerned, it is more interesting and important to know if CD inclusion will change the environmental behavior and the fate of organic pollutants and if there could be any possibility to make use of $C D$ in pollutants control (Zhang et al. 2007). Attarchi et al. prepared $\mathrm{Ag} / \mathrm{TiO}_{2} / \beta$-CD nanocomposite and tested its photocatalytic activity for degradation of methylene blue dye (Attarchi et al. 2013), Yang et al. (2014) reported the selfassembly of bioinspired catecholic cyclodextrin $\mathrm{TiO}_{2}$ 
heterosupramolecule with high adsorption capacity and efficient visible-light photoactivity, photodegradation of 4,4-bis(4-hydroxyphenyl)valeric acid and its inclusion complex with $\beta$-cyclodextrin in aqueous solution (Salomatova et al. 2014) has been reported recently.

We have reported photocatalytic decoloration of dyes with $\mathrm{TiO}_{2} / \beta-\mathrm{CD}$ and $\mathrm{ZnO} / \beta-\mathrm{CD}$ using visible, $\mathrm{UV}$ and solar light and the results were compared with bare $\mathrm{TiO}_{2}$ and $\mathrm{ZnO}$ (Velusamy et al. 2011, 2013; Rajalakshmi et al. 2013; Pitchaimuthu et al. 2013; Velusamy et al. 2014). The present study is aimed to investigate the feasibility of solar light for photocatalytic decoloration of RhB dye in different conditions. The effect of various parameters such as initial dye concentration, irradiation time, amount of catalysts and $\mathrm{pH}$ have been investigated on the photocatalytic decoloration of $\mathrm{RhB}$ in the presence of $\mathrm{TiO}_{2} / \beta-\mathrm{CD}$ and $\mathrm{ZnO} / \beta-\mathrm{CD}$ as a photocatalyst and the results were compared with bare $\mathrm{TiO}_{2}$ and $\mathrm{ZnO}$. The mineralization of $\mathrm{RhB}$ dye was further confirmed by Chemical Oxygen Demand (COD). A decoloration pathway based on GC-MS was studied to confirm the photocatalytic decoloration of $\mathrm{RhB}$ dye.

\section{Experimental}

\section{Materials}

$\mathrm{RhB}$ dye obtained from Loba Chemie (India) was used as such. The catalysts viz, $\mathrm{TiO}_{2}$ and $\mathrm{ZnO}$ were received from $\mathrm{SD}$ fine chemicals, India. $\beta-\mathrm{CD}$ was purchased from $\mathrm{Hi}$ Media Chemicals (P) Ltd. All the other chemicals and reagents were used as received.

\section{Samples preparation}

Reported procedures were employed for the preparation of $\mathrm{RhB} / \beta-\mathrm{CD}$ complex (Pitchumani et al. 1994; Velusamy et al. 2011, 2014). To a saturated solution of $\beta-C D$ in distilled water, equimolar amount of $\mathrm{RhB}$ dye was added and stirred continuously for $24 \mathrm{~h}$. The precipitated inclusion complex was filtered and washed with diethyl ether to remove uncomplexed $\mathrm{RhB}$ dye and dried in an air oven at $60{ }^{\circ} \mathrm{C}$ for $2-3 \mathrm{~h}$. The precipitate thus obtained is used for the characterization of $\mathrm{RhB} / \beta-\mathrm{CD}$ complex by FT-IR and ${ }^{1} \mathrm{H}$ NMR analyses.

Metal oxides (MOs) such as $\mathrm{TiO}_{2}$ and $\mathrm{ZnO}$ were added into $0.01 \mathrm{~mol} / \mathrm{L} \beta-\mathrm{CD}$ solution and stirred for $20 \mathrm{~min}$. The suspended solution was centrifuged; the solids were separated and washed three times with water. The solids were dried with an infrared lamp for UV-DRS, PXRD and FESEM analyses (Lu et al. 2004).
Exactly $10 \times 10^{-6} \mathrm{M}$ of RhB dye was prepared using deionised water and various concentrations of $\beta$-CD like $1.25,2.50,3.75,5.00,6.25$ and $7.50 \times 10^{-5} \mathrm{M}$ were prepared in a $25 \mathrm{~mL}$ SMF. These two solutions were mixed thoroughly with magnetic stirrer for $24 \mathrm{~h}$. Then these samples were analyzed with UV-visible spectrophotometer (Velusamy 1998).

For GC-MS analysis, the photocatalytic decoloration experiments were carried out under different irradiation times and irradiated samples were collected. The dye solution was extracted using $\mathrm{CHCl}_{3}$ as a solvent. The solvent was evaporated. The residue was then used for the analyses.

\section{Characterization}

X-ray diffraction patterns of powder samples were recorded with a high-resolution powder X-ray diffractometer model RICH SIERT \& Co with $\mathrm{CuK}_{\alpha}$ radiation as the $\mathrm{X}$-ray source $\left(\lambda=1.5406 \times 10^{-10} \mathrm{~m}\right)$. FE-SEM images were obtained on a Carl ZEISS ( $\Sigma$ IGMA Series, Germany) microscope taken at an accelerated voltage of $2 \mathrm{kV}$. UV-visible diffuse reflectance spectra were recorded on a Shimadzu 2550 UV-visible spectrophotometer with $\mathrm{BaSO}_{4}$ as the background between 200 and $700 \mathrm{~nm}$. NMR spectra were recorded at $400 \mathrm{MHz}$ Bruker NMR spectrometer (in DMSO- $\mathrm{d}_{6}$ ). UV-visible spectra were recorded using UV-visible spectrophotometer (Shimadzu UV-1700) and the scan range was from 400 to $800 \mathrm{~nm}$. FT-IR spectra were recorded using FT-IR spectrometer (Shimadzu model 8400S) in the region $4,000-400 \mathrm{~cm}^{-1}$ using $\mathrm{KBr}$ pellets. Absorbance of the dye was determined with visible spectrophotometer (ELICO-207). The $\mathrm{pH}$ of the dye solution was measured using digital pen $\mathrm{pH}$ meter (HANNA instrument, Portugal). The GC-MS spectra was recorded by GC (Perkin-Elmer Auto System) equipped with an HP5MS capillary column $(30 \times 250$ micron $)$ and $1-\mu \mathrm{m}$ film thickness (Perkin-Elmer elite series) and interfaced directly to the MS (Perkin-Elmer turbo mass spectrophotometer). The GC column was operated at a temperature of $50{ }^{\circ} \mathrm{C}$ for $2 \mathrm{~min}$ then increased to $280{ }^{\circ} \mathrm{C}$ at the rate of $10^{\circ} \mathrm{C} / \mathrm{min}$ in split mode. Injection volume $0.1 \mu \mathrm{L}$ with helium as carrier gas was used. The other analytical conditions are: EI impact ionization $70 \mathrm{eV}$, injection temperature $280^{\circ} \mathrm{C}$, source temperature $180{ }^{\circ} \mathrm{C}$.

Photocatalytic experiments

All experiments were carried out under identical conditions using Borosilicate beakers as the sample holders. Exactly $50 \mathrm{~mL}$ of $\mathrm{RhB}$ dye solution with required amount of 
catalysts and at definite concentration was irradiated under solar light. Prior to irradiation, the reaction mixture was stirred in the dark for $20 \mathrm{~min}$ to achieve adsorption saturation. At regular intervals, $5 \mathrm{~mL}$ of the sample was taken out and centrifuged to remove the catalysts. Absorbance at $544 \mathrm{~nm}$ was measured to determine the concentration of $\mathrm{RhB}$ after the photocatalytic decoloration process. The photocatalytic reaction was carried out during the daytime. The light intensity during the photocatalytic reaction was measured using lux meter (between 11.30 AM to 1.30 PM) and found that it was in the range of 944-1,090 lux. COD analyses were done by open reflux method (Alhakimi et al. 2003).

\section{Results and discussion}

Characterization of photocatalysts

\section{Optical properties}

UV-visible diffuse reflectance spectra of $\mathrm{TiO}_{2}, \mathrm{ZnO}, \mathrm{TiO}_{2} /$ $\beta-\mathrm{CD}$ and $\mathrm{ZnO} / \beta-\mathrm{CD}$ give information about the optical properties of the catalysts. The reflectance data reported as $(\alpha h v)^{2}(\mathrm{eV})^{2}$ values have been obtained by the application of the Kubelka-Munk algorithm. The band gaps of the catalysts have been deduced from the Tauc plot. Figure 1 indicates the plot of $(\alpha h v)^{2}(\mathrm{eV})^{2}$ vs energy. The extrapolation of the rising segment of $(\alpha h v)^{2}(\mathrm{eV})^{2}$ to the abscissa at zero $\mathrm{F}^{\circledR}$ provides the band gap energy as $3.35 \mathrm{eV}$ for $\mathrm{TiO}_{2}$, $3.27 \mathrm{eV}$ for $\mathrm{ZnO}, 3.31 \mathrm{eV}$ for $\mathrm{TiO}_{2} / \beta-\mathrm{CD}$ and $3.23 \mathrm{eV}$ for $\mathrm{ZnO} / \beta-\mathrm{CD}$ nanocomposites. The results showed that the band gap energy of $\mathrm{MO} / \beta-\mathrm{CD}$ nanocomposites is lower

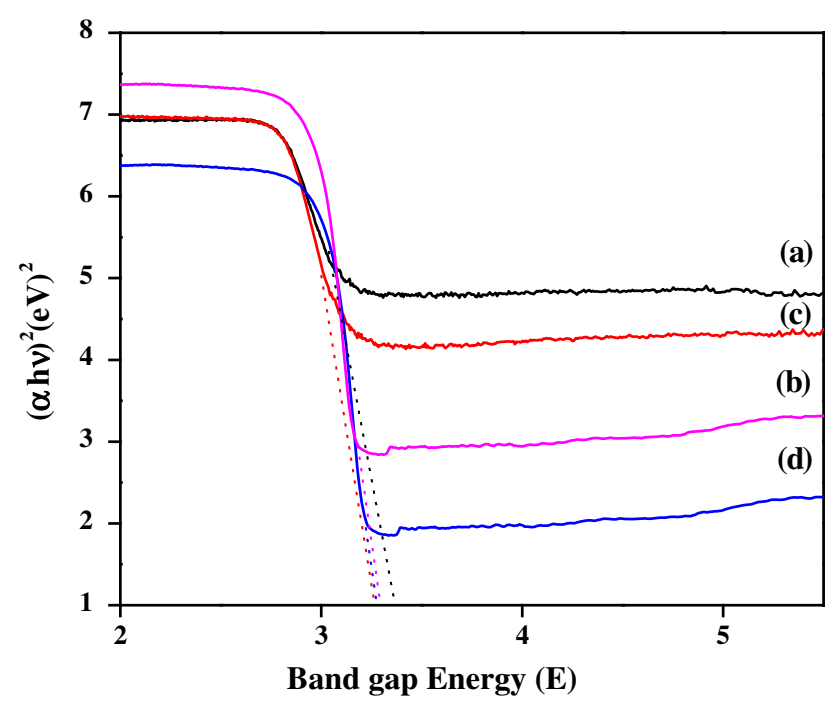

Fig. 1 Diffuse reflectance spectra of $a \mathrm{TiO}_{2}, b \mathrm{ZnO}, c \mathrm{TiO}_{2} / \beta-\mathrm{CD}$, $d \mathrm{ZnO} / \beta-\mathrm{CD}$ than the corresponding metal oxides. Therefore, $\mathrm{MO} / \beta-\mathrm{CD}$ nanocomposites can be excited to produce more electronhole pairs under same light illumination which could result in higher photocatalytic activity (Karunakaran et al. 2010).

\section{Phase structure}

The XRD patterns of $\mathrm{TiO}_{2} / \beta-\mathrm{CD}$ and $\mathrm{ZnO} / \beta-\mathrm{CD}$ nanocomposites are similar to that of $\mathrm{TiO}_{2}$ and $\mathrm{ZnO}$ particles (Rajalakshmi et al. 2013). The XRD analysis of $\mathrm{TiO}_{2}$ reveals that the sample exhibits single phase belongs to anatase-type $\mathrm{TiO}_{2}$ which is identified by comparing the spectra with the JCPDS file \# 21-1272 (Velusamy et al. 2014; Pitchaimuthu et al. 2013). Diffraction peaks at $25.38^{\circ}, 37.90^{\circ}, 48.07^{\circ}, 53.94^{\circ}$ and $55.18^{\circ}$ correspond to (101), (004), (200), (105) and (211) planes of $\mathrm{TiO}_{2}$, respectively. The XRD spectra of $\mathrm{ZnO}$ and $\mathrm{ZnO} / \beta-\mathrm{CD}$ composites provide all of the characteristic peaks which are well matched with that of hexagonal wurtzite $\mathrm{ZnO}$ (JCPDS file \# 36-1451) (Velmurugan and Swaminathan 2011). The relatively high intensity of the peak for (101) plane is an indicative of anisotropic growth and implies a preferred orientation of the crystallites. The peaks corresponding to the MOs exhibit appreciable differences in $\mathrm{MO} / \beta-\mathrm{CD}$ nanocomposites. In particular, the peaks related to $\beta-\mathrm{CD}$ of $2 \theta$ values from $12.38^{\circ}$ to $12.70^{\circ}$ are hidden and the peaks of $2 \theta$ values are getting reduced when it is blended with $\mathrm{TiO}_{2}$. In the same way, the peaks correspond to $\mathrm{ZnO}$ of $2 \theta$ values at $31.74^{\circ}, 31.76^{\circ}, 31.78^{\circ}$ and $36.18^{\circ}$ to $36.36^{\circ}$ are getting reduced when $\mathrm{ZnO}$ is blended with $\beta-C D$. All the above evidences imply that there is a strong binding between $\beta-\mathrm{CD}$ and MOs. This indicates that the incorporation of $\beta-\mathrm{CD}$ on MOs provide no change in the crystalline structure of the bare $\mathrm{TiO}_{2}$ and $\mathrm{ZnO}$. But the main peak intensity of the both $\mathrm{TiO}_{2} / \beta-\mathrm{CD}$ and $\mathrm{ZnO} /$ $\beta$-CD nanocomposites are slightly lower than bare $\mathrm{TiO}_{2}$ and $\mathrm{ZnO}$.

\section{Morphology}

The morphology of the samples was investigated by FESEM analyses. Figure $2 \mathrm{a}-\mathrm{e}$ depicts FE-SEM of $\beta-C D$, $\mathrm{TiO}_{2}, \mathrm{ZnO}, \mathrm{TiO}_{2} / \beta-\mathrm{CD}$ and $\mathrm{ZnO} / \beta-\mathrm{CD}$ nanocomposites, respectively. The surface morphology of pristine $\beta-C D$ (Fig. 2a) shows its amorphous nature. $\mathrm{TiO}_{2}$ crystals have spherical morphology with uniform particle size (Fig. 2b). ZnO has prismatic morphology with uniform particles containing wurtzite lattice structure (Fig. 2c). Whereas in $\mathrm{TiO}_{2} / \beta-\mathrm{CD}$ nanocomposites (Fig. 2d) and $\mathrm{ZnO} / \beta$-CD (Fig. 2e), two different types of particles are observed. The smaller size particles correspond to $\beta-\mathrm{CD}$ and larger particles correspond to MOs such as $\mathrm{TiO}_{2}$ and $\mathrm{ZnO}$. This indicates that the $\beta-\mathrm{CD}$ molecules are

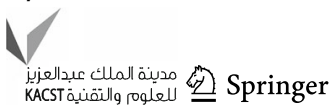




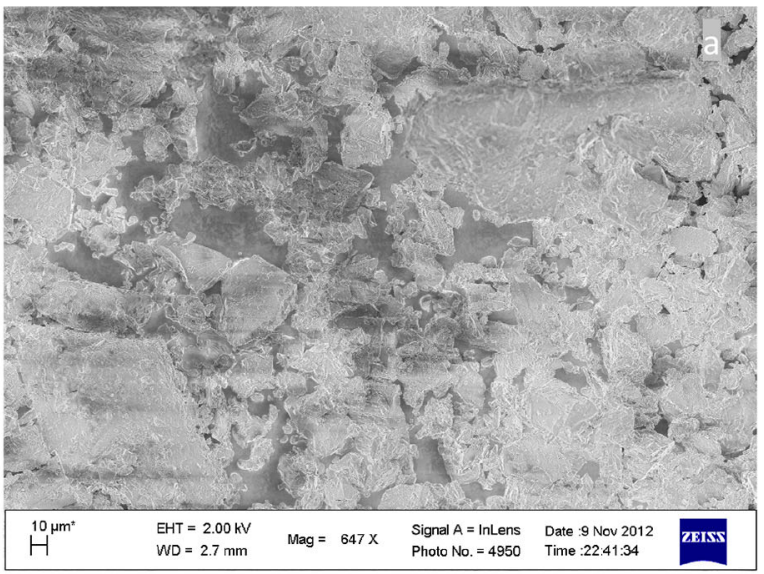

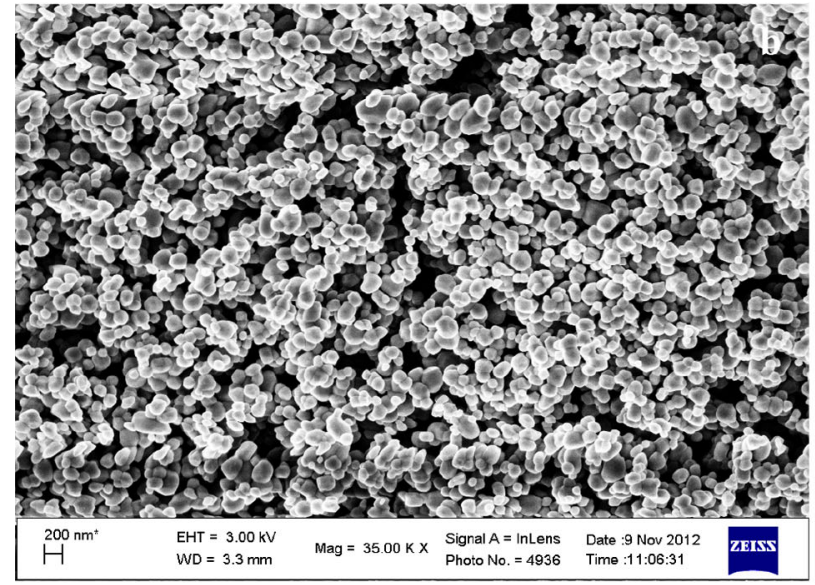

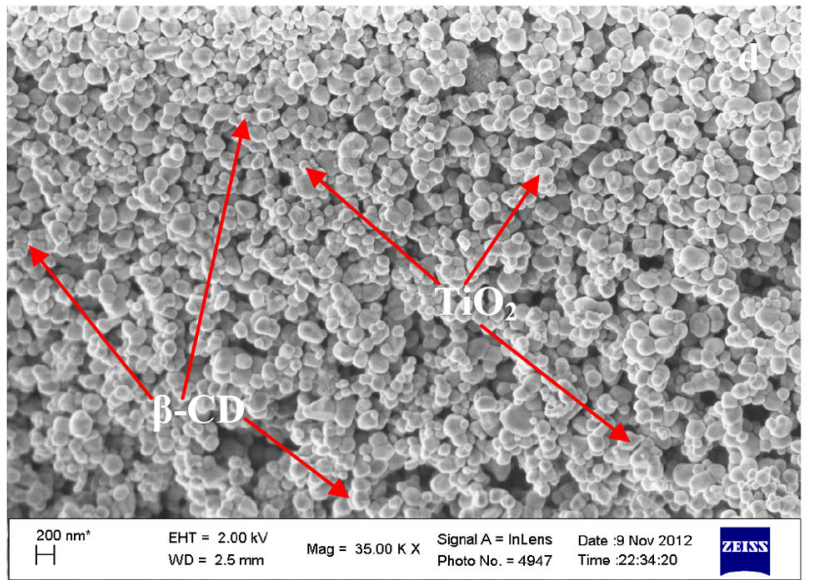

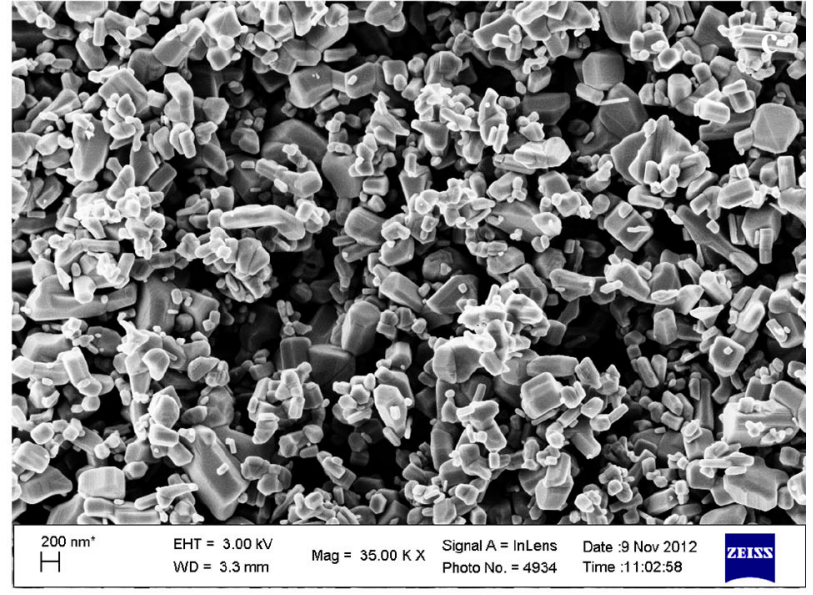

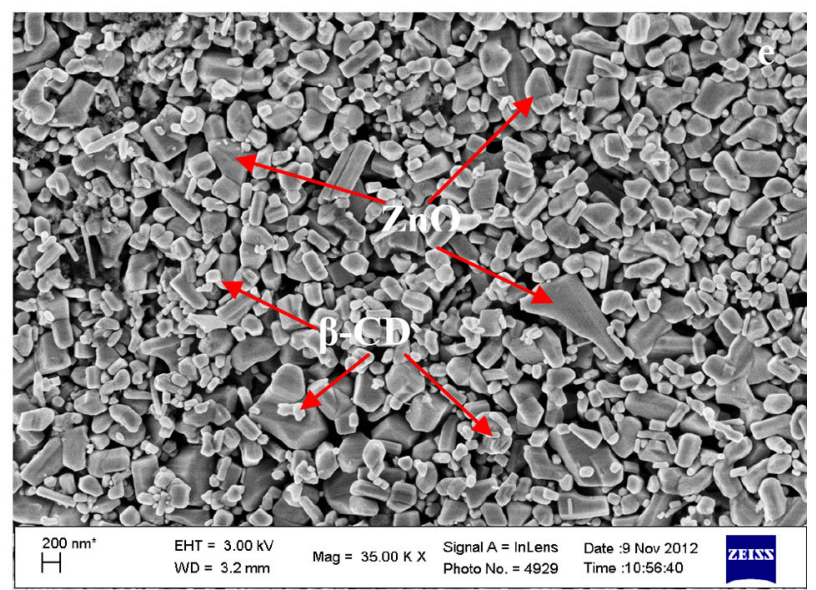

Fig. 2 FE-SEM images of a $\beta$-CD, b $\mathrm{TiO}_{2}$, $\mathbf{~ Z n O , ~} \mathbf{d} \mathrm{TiO}_{2} / \beta-\mathrm{CD}$, e $\mathrm{ZnO} / \beta-\mathrm{CD}$

adsorbed on the surface of the metal oxides. It is also observed that the surface of $\mathrm{MO}$ nanocomposites $\left(\mathrm{TiO}_{2} /\right.$ $\beta-\mathrm{CD}$ and $\mathrm{ZnO} / \beta-\mathrm{CD})$ is very loosely backed in nature. This kind of surface can provide a better adsorption environment and more active sites for the photocatalytic decoloration reactions.
Evidence for complex formation

\section{Dissociation constant measurement}

Based on UV-absorption spectral studies (using the Benesi and Hildebrand equation) (Pitchumani et al. 1994; 


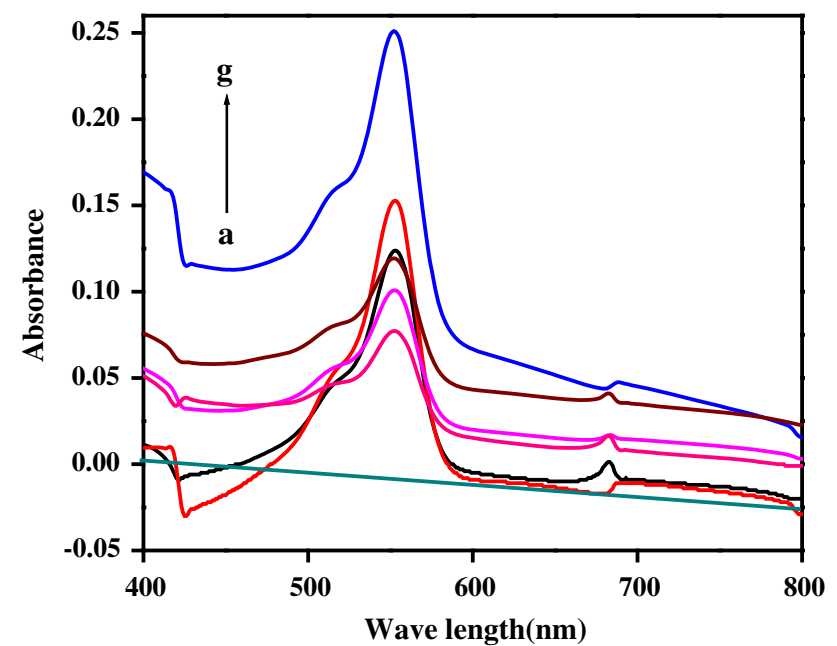

Fig. 3 UV-visible spectra for complexation of $\mathrm{RhB} / \beta-\mathrm{CD} a \beta-\mathrm{CD}$,

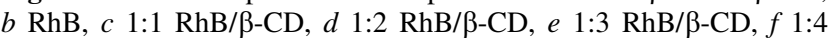
$\mathrm{RhB} / \beta-\mathrm{CD}, g$ 1:5 RhB/ $\beta-\mathrm{CD}$

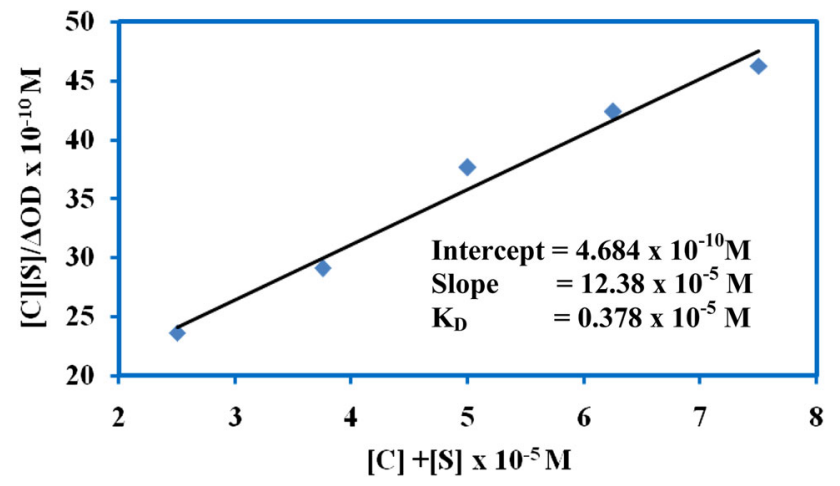

Fig. 4 Plot of $[\mathrm{C}][\mathrm{S}] / \Delta$ OD vs $\{[\mathrm{C}]+[\mathrm{S}]\}$ for $\mathrm{RhB} / \beta-\mathrm{CD}$ complex

Velusamy 1998), the dissociation constant $\left(K_{\mathrm{D}}\right)$ is evaluated as $0.378 \times 10^{-5} \mathrm{M}$ (Figs. 3, 4). The value of $\mathrm{K}_{\mathrm{D}}$ indicated that the dye molecules form strong inclusion complex with $\beta$-CD.

\section{FT-IR spectra}

FT-IR techniques are not generally utilized for the detection of inclusion compounds because the resultant spectra have super position of host and guest bands. However, in this study $\mathrm{RhB}$ dye has some characteristics FT-IR absorption in regions where $\beta$-CD does not show absorption in the corresponding regions is used to identify the host-guest interaction (Velusamy et al. 1996). FT-IR spectra of complexation between RhB dye and $\beta$-CD (1:1) and its physical mixture (1:1) are presented in Fig. 5. The aromatic - $-\mathrm{C}-\mathrm{H}$ stretching of $\mathrm{RhB}$ is observed at $2,977.89 \mathrm{~cm}^{-1}$ is shifted with reduced intensity to $2,972.74 \mathrm{~cm}^{-1}$ in the $\mathrm{RhB} / \beta-\mathrm{CD}$ complex. Similarly, the peaks at the frequencies $1,640.17,1,577.66,1,640$ and

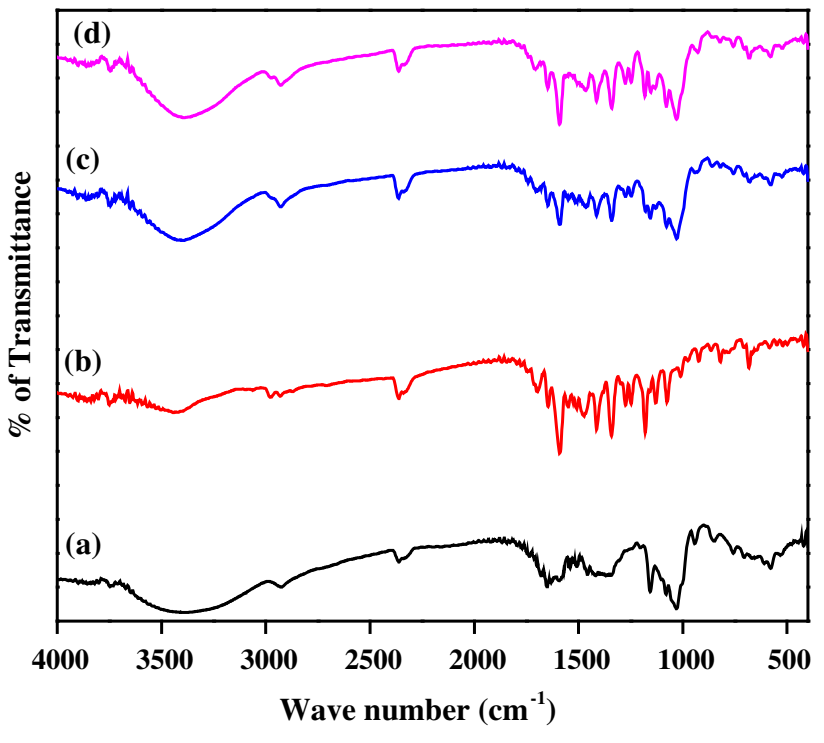

Fig. 5 FT-IR spectra of $a \beta-\mathrm{CD}, b$ RhB, $c$ 1:1 physical mixture of $\mathrm{RhB} / \beta-\mathrm{CD}, d 1: 1$ complex of $\mathrm{RhB} / \beta-\mathrm{CD}$ ( $\mathrm{KBr}$ pellets)

$894.91 \mathrm{~cm}^{-1}$ corresponding to the functional groups such as $-\mathrm{COOH},-\mathrm{C}=\mathrm{C}-,-\mathrm{C}-\mathrm{N}=$ and $-\mathrm{C}-\mathrm{O}-\mathrm{C}-$ are shifted to $1,706.88,1,589.23,1,647.10$ and $1,182.28 \mathrm{~cm}^{-1}$, respectively, in the $\mathrm{RhB} / \beta-\mathrm{CD}$ complex. It indicates that there is a strong inclusion complex between $\mathrm{RhB}$ and $\beta-\mathrm{CD}$.

\section{${ }^{1} H$ NMR analysis}

Formation of an inclusion complex between $\mathrm{RhB}$ and $\beta-\mathrm{CD}$ was also inferred from ${ }^{1} \mathrm{H}$ NMR studies of $\mathrm{RhB} / \beta-\mathrm{CD}$ complex. The chemical shifts (in ppm) given for $\beta$-CD protons are shifted in RhB/ $\beta-\mathrm{CD}$ complex (Fig. 6; Table 1). The upfield shift was occurred for $\mathrm{H}_{1}$ and $\mathrm{H}_{3}$ and $\mathrm{H}_{5}$, which are located in the inner side of $\beta-\mathrm{CD}$. The changes of chemical shift $(\Delta \delta)$ of $\mathrm{H}_{3}$ and $\mathrm{H}_{5}$ suggested that the $\mathrm{RhB}$ dye molecules are encapsulated into the hydrophobic cavity of $\beta-\mathrm{CD}$. On the contrary, the chemical shifts of $\mathrm{H}_{2}$ and $\mathrm{H}_{4}$ which are located on the outer surface of $\beta-\mathrm{CD}$ and the narrow opening of $\beta$ $\mathrm{CD}$, undergo downfield shift by the RhB dye molecules. $\mathrm{H}_{6}$ proton does not undergo any changes. Similarly, for $\mathrm{RhB}$ protons there is no change in $\mathrm{H}_{c}$ protons and $\mathrm{H}_{\mathrm{a}}$ and $\mathrm{H}_{\mathrm{b}}$ protons are shifted to upfield because of the interaction between RhB and $\beta$-CD (Table 2). These observations are consistent with the notation that the phenyl ring of $\mathrm{RhB}$ dye molecule is suitably encapsulated into the $\beta-C D$ cavity.

Assessment of photocatalytic activity

\section{Effect of initial concentration}

The photocatalytic decoloration of $\mathrm{RhB}$ dye was carried out by varying the initial concentration of the dye and 


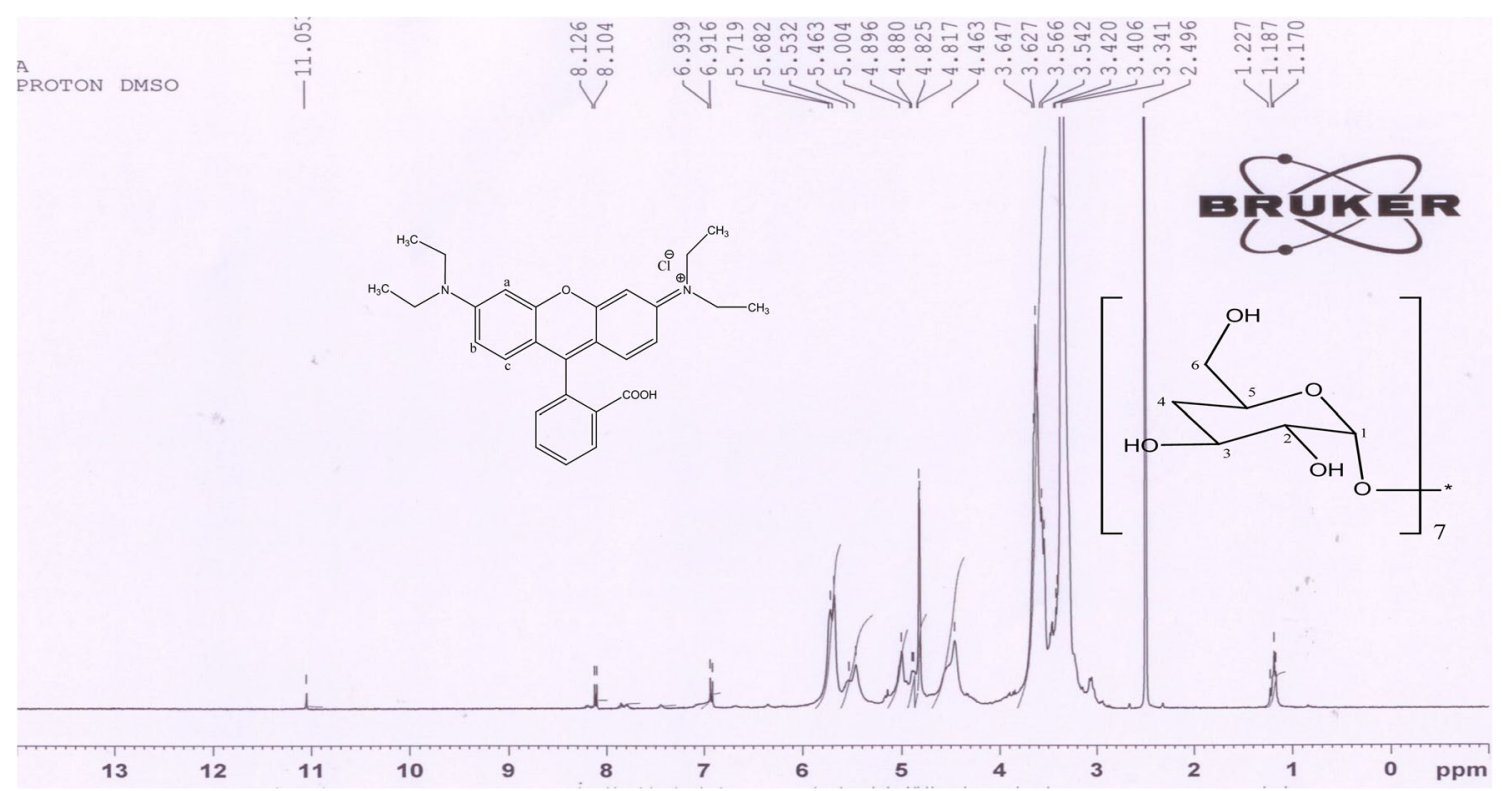

Fig. $6{ }^{1} \mathrm{H}$ NMR spectra of RhB/ $\beta-C D$ inclusion complex (DMSO-d ${ }_{6}$ )

Table $1{ }^{1} \mathrm{H}$ NMR chemical shifts of $\beta-\mathrm{CD}$ protons in $\mathrm{RhB} / \beta-\mathrm{CD}$ complex

\begin{tabular}{lllllll}
\hline & $\mathrm{H}_{1}$ & \multicolumn{1}{l}{$\mathrm{H}_{2}$} & \multicolumn{1}{l}{$\mathrm{H}_{3}$} & \multicolumn{1}{l}{$\mathrm{H}_{4}$} & \multicolumn{1}{l}{$\mathrm{H}_{5}$} & $\mathrm{H}_{6}$ \\
\hline$\beta-\mathrm{CD}$ & 5.03 & 4.00 & 3.73 & 3.02 & 3.73 & 3.54 \\
$\mathrm{RhB} / \beta-\mathrm{CD}$ & 5.00 & 4.46 & 3.65 & 3.34 & 3.65 & 3.54 \\
$\Delta \delta$ & 0.03 & -0.46 & 0.08 & -0.32 & 0.08 & 0.00 \\
\hline
\end{tabular}

Chemical shifts values are expressed in ppm

Table $2{ }^{1} \mathrm{H}$ NMR chemical shifts of $\mathrm{RhB}$ protons in $\mathrm{RhB} / \beta-\mathrm{CD}$ complex

\begin{tabular}{llll}
\hline & $\mathrm{H}_{\mathrm{a}}$ & $\mathrm{H}_{\mathrm{b}}$ & $\mathrm{H}_{\mathrm{c}}$ \\
\hline $\mathrm{RhB}$ & 5.85 & 5.94 & 6.91 \\
$\mathrm{RhB} / \beta-\mathrm{CD}$ & 5.53 & 5.72 & 6.91 \\
$\Delta \delta$ & 0.32 & 0.22 & 0.00
\end{tabular}

Chemical shifts values are expressed in ppm

fixing all other processing parameters constant. Figure 7 shows that the percentage of decoloration decreases with increase in initial concentration of $\mathrm{RhB}$ from 95.0 to $60.0 \%$ for $\mathrm{TiO}_{2}, 97.0-66.0 \%$ for $\mathrm{ZnO}, 98.8-76.0 \%$ for $\mathrm{TiO}_{2} / \beta-\mathrm{CD}$ and $99.0-84.0 \%$ for $\mathrm{ZnO} / \beta-\mathrm{CD}$ nanocomposite. The possible explanation for this behavior is that as the initial concentration of the dye increases (1) the path length of the photons entering into the solution decreases and in low concentration the reverse effect is observed, thereby increasing the number of photon absorption by the catalyst in lower concentration and hence percentage of decoloration decreases. (2) Due to

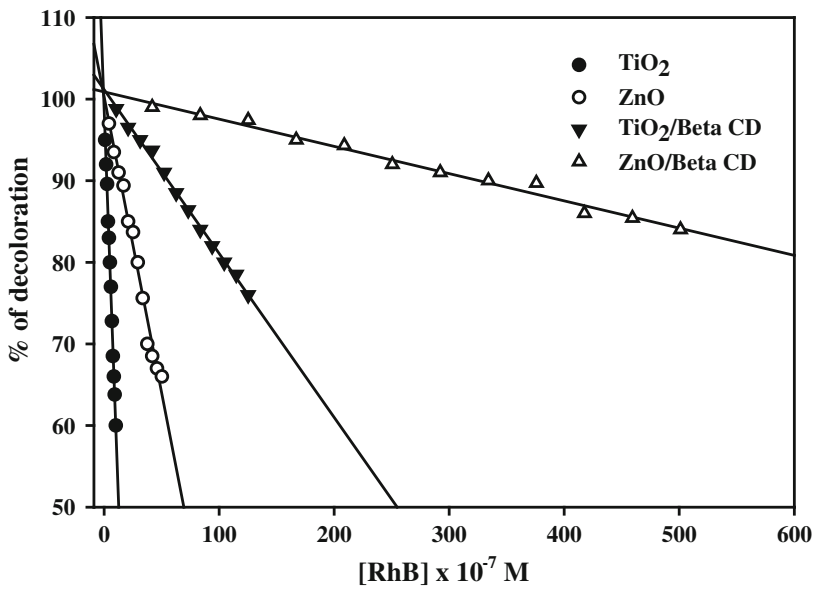

Fig. 7 Effect of initial concentration on photocatalytic decoloration of $\mathrm{RhB}$ dye under solar light irradiation time $=120 \mathrm{~min}$; dose $=2 \mathrm{~g}$ / $\mathrm{L} ; \mathrm{pH}=3.6$

the lack of active sites with the increase in the initial concentration of RhB, the amount of dye adsorbed on the catalyst surface gets increased. Due to this, only fewer photons reach at the surface of photocatalyst. This results decrease in concentration of ${ }^{\bullet} \mathrm{OH}$ and $\mathrm{O}_{2}^{\bullet-}$ radicals thereby decrease in photocatalytic decoloration activity (Wang et al. 2008; Aliabadi and Sagharigar 2011; Dong et al. 2010). From the results it was also inferred that the $167 \times 10^{-7} \mathrm{M}$ concentration of $\mathrm{RhB}$ dye was decolorized up to $95.0 \%$ using $\mathrm{ZnO} / \beta-\mathrm{CD}$ nanocomposite at the optimum reaction conditions such as irradiation time $=120 \mathrm{~min} ; \quad$ dose $=2 \mathrm{~g} / \mathrm{L}$ and $\mathrm{pH}=3.6$. 


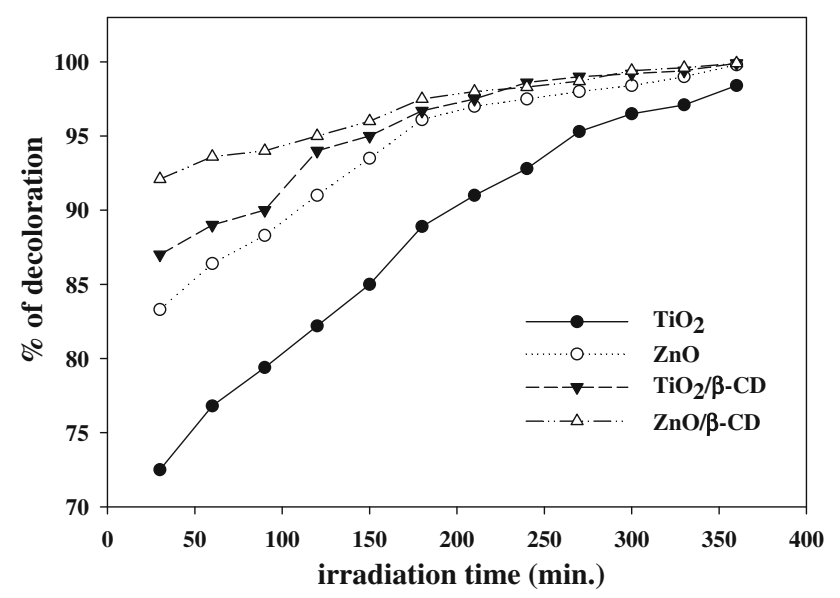

Fig. 8 Effect of irradiation time on photocatalytic decoloration of $\mathrm{RhB}$ dye under solar light irradiation. $[\mathrm{RhB}]=4.1 \times 10^{-7} \mathrm{M}$ for $\mathrm{TiO}_{2}, 16.7 \times 10^{-7} \mathrm{M}$ for $\mathrm{ZnO}, 41.7 \times 10^{-7} \mathrm{M}$ for $\mathrm{TiO}_{2} / \beta-\mathrm{CD}$, $167 \times 10^{-7} \mathrm{M}$ for $\mathrm{ZnO} / \beta-\mathrm{CD}$; dose $=2 \mathrm{~g} / \mathrm{L} ; \mathrm{pH}=3.6$

\section{Effect of irradiation time}

The effect of irradiation time for the removal of $\mathrm{RhB}$ dye by semiconductor mediated photocatalysis is shown in Fig. 8. It has been found that with the increase in irradiation time, percentage of decoloration increases from 72.5 to $98.4 \%$ for $\mathrm{TiO}_{2}, 83.3-99.8 \%$ for $\mathrm{ZnO}, 87.0-99.9 \%$ for $\mathrm{TiO}_{2} / \beta-\mathrm{CD}$ and $92.1-99.9 \%$ for $\mathrm{ZnO} / \beta-\mathrm{CD}$ nanocomposite. This is attributed to the fact that, as the irradiation time is increased, the dye molecules have enough time to react with the catalysts and form hydroxyl radicals which accelerate photocatalytic decoloration reaction and also as time proceeds, this concentration gradient decreases due to accumulation of dye molecules on vacant sites and thus saturation stage was almost perceived and hence percentage of decoloration increases (Daneshvar et al. 2003a, b).

\section{Kinetics of photocatalytic decoloration}

Reaction kinetics gives enough information about the reaction rates and the mechanisms by which the reactants are converted to the products. Kinetics is determined for all the catalysts as $\ln C_{0} / C_{t}$ vs irradiation time after the photocatalytic decoloration process (Fig. 9). The results showed that the photocatalytic decoloration of $\mathrm{RhB}$ obeys apparently pseudo-first-order kinetics and the rate expression is given by

$\ln C_{0} / C_{t}=k t$

where $C_{t}$ is the concentration of $\mathrm{RhB}$ at time $t, C_{0}$ is the initial concentration of $\mathrm{RhB}$ and $k$ is the pseudo-first-order rate constant (Wang et al. 2009a, b).

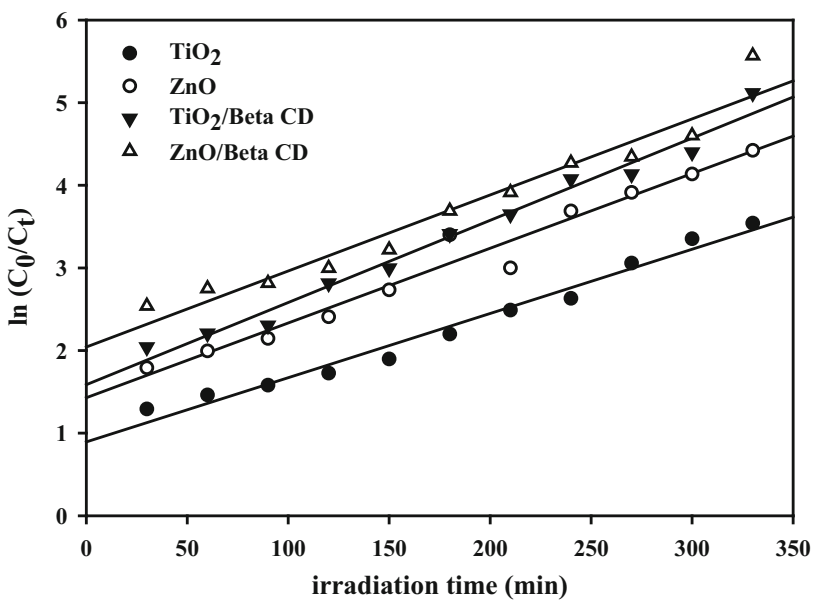

Fig. 9 Kinetics of photocatalytic decoloration of $\mathrm{RhB}$ dye under solar light irradiation

\section{Effect of amount of catalysts}

Effect of amount of catalysts is an important factor that affects the photocatalytic decoloration reactions. Experiments were performed by varying the amount of catalysts from 0.6 to $7.2 \mathrm{~g} / \mathrm{L}$. The results (Fig. 10) showed that the percentage of photocatalytic decoloration increased by increasing the amount of catalysts from 76.5 to $89.5 \%$ for $\mathrm{TiO}_{2}, 85.0-96.8 \%$ for $\mathrm{ZnO}, 88.0-98.8 \%$ for $\mathrm{TiO}_{2} / \beta-\mathrm{CD}$ and $90.5-99.5 \%$ for $\mathrm{ZnO} / \beta-\mathrm{CD}$ nanocomposite. Irrespective of the nature of the dye and photocatalysts, the percentage of removal was found to enhance linearly (certain level) with increase in the dose of the catalyst indicating the heterogeneous regime. This may probably be due to: (1) increase in the extent of dye adsorption molecules on the catalyst surface; (2) increase in the number of surface active sites; (3) enhanced generation of hydroxyl radicals due to increase in the concentration of charge carriers. However, at higher amount of catalyst, the reaction rate tends to decrease which may be attributed to; (1) the deactivation of activated molecules by collision with ground state molecules; (2) the agglomeration of the catalyst particles at higher amount of catalysts, which covers the part of photosensitive area retarding the photon absorption and also the dye adsorption; (3) turbidity at higher amount of catalysts results in the shadowing effect thus decreasing the penetration depth of light irradiation; (4) high degree of scattering by the catalyst particles and increase in the opacity. Hence above a certain level, the additional catalyst amount does not get involved in catalytic activity and further increment in the reaction rate was not observed. Hence, the optimum level of dose is $2 \mathrm{~g} / \mathrm{L}$ (Daneshvar et al. 2003a, b; Grzechulska and Morawski 2002; Wang et al. 2009a, b; Rauf and Salman Ashraf 2009; Damardji et al. 2009; Chen et al. 2004). 


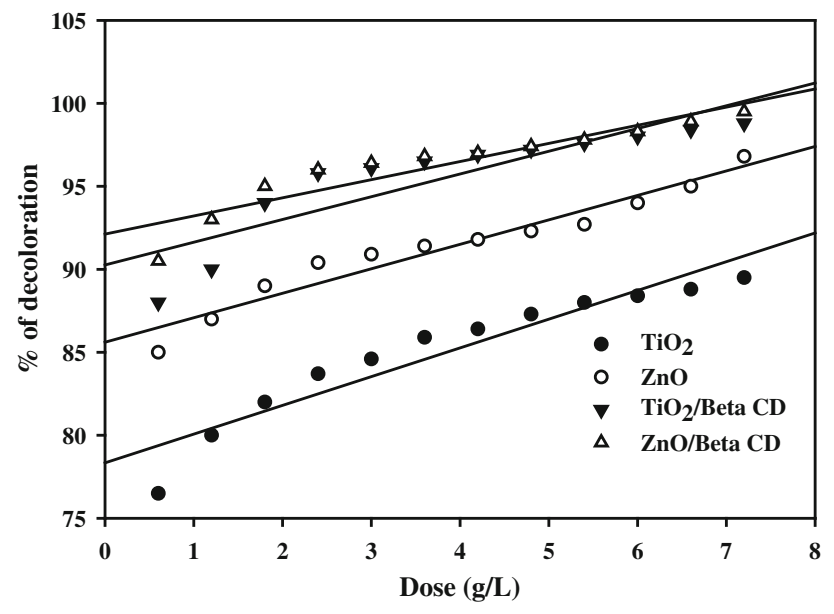

Fig. 10 Effect of amount of catalysts on photocatalytic decoloration of RhB dye under solar light irradiation. $[\mathrm{RhB}]=4.1 \times 10^{-7} \mathrm{M}$ for $\mathrm{TiO}_{2}, 16.7 \times 10^{-7} \mathrm{M}$ for $\mathrm{ZnO}, 41.7 \times 10^{-7} \mathrm{M}$ for $\mathrm{TiO}_{2} / \beta-\mathrm{CD}$, $167 \times 10^{-7} \mathrm{M}$ for $\mathrm{ZnO} / \beta-\mathrm{CD}$; irradiation time $=120 \mathrm{~min}$; $\mathrm{pH}=3.6$

\section{Effect of $p H$}

The $\mathrm{pH}$ of the aqueous solution is an important variable in the evaluation of aqueous phase-mediated photocatalytic reactions. The effect of $\mathrm{pH}$ on the photocatalytic decoloration of $\mathrm{RhB}$ dye was studied under constant experimental conditions such as amount of catalysts $(2 \mathrm{~g} / \mathrm{L})$, irradiation time $(120 \mathrm{~min})$ and concentration of the dye $\left[4.1 \times 10^{-7} \mathrm{M}\right.$ $\left(\mathrm{TiO}_{2}\right) ; 16.7 \times 10^{-7} \mathrm{M}(\mathrm{ZnO}) ; 41.7 \times 10^{-7} \mathrm{M}\left(\mathrm{TiO}_{2} / \beta-\right.$ $\left.\mathrm{CD}) ; 167 \times 10^{-7} \mathrm{M}(\mathrm{ZnO} / \beta-\mathrm{CD})\right]$. The experiments were carried out by changing in the initial $\mathrm{pH}$ value of the dye from 1 to 12. It has been observed from Fig. 11 that the percentage of decoloration increased considerably with an increase in $\mathrm{pH}$ from 78.0 to $92.8 \%$ for $\mathrm{TiO}_{2}, 86.0-95.8 \%$ for $\mathrm{ZnO}, 86.9-98.6 \%$ for $\mathrm{TiO}_{2} / \beta-\mathrm{CD}$ and $90.0-99.8 \%$ for $\mathrm{ZnO} / \beta-\mathrm{CD}$ nanocomposite and it showed percentage of decoloration is higher at strong basic condition than the neutral $\mathrm{pH}$. The reason is under alkaline conditions, the concentrations of perhydroxyl radicals and hydroxide ions are getting increased. During catalyst-based photochemical reactions, both perhydroxyl as well as hydroxyl ions produce large number of hydroxyl radicals in the aqueous medium, which effectively take part in the decoloration of organic pollutants present in RhB dye (Wang et al. 2009a, b; Kansal et al. 2008; Santhi et al. 2011).

$\mathrm{pH}>\mathrm{pH}_{\mathrm{ZPC}} \mathrm{M}-\mathrm{OH}+\mathrm{OH}^{-} \rightarrow \mathrm{MO}^{-}+\mathrm{H}_{2} \mathrm{O}$

$\mathrm{pH}<\mathrm{pH}_{\mathrm{ZPC}} \mathrm{M}-\mathrm{OH}+\mathrm{H}^{+} \rightarrow \mathrm{MOH}_{2}^{+}$

The $\mathrm{pH}$ of the reaction has a significant effect on the surface properties of the metal oxide photocatalysts, which include the surface charge of the particles, the extent of aggregation of the catalyst particles, and the band edge

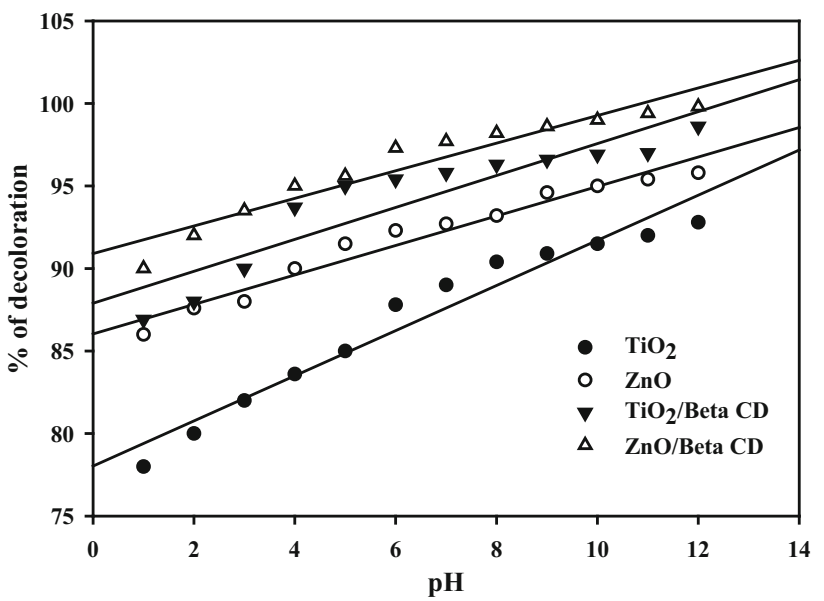

Fig. 11 Effect of $\mathrm{pH}$ on photocatalytic decoloration of $\mathrm{RhB}$ dye under solar light irradiation. $[\mathrm{RhB}]=4.1 \times 10^{-7} \mathrm{M}$ for $\mathrm{TiO}_{2}$, $16.7 \times 10^{-7} \mathrm{M}$ for $\mathrm{ZnO}, \quad 41.7 \times 10^{-7} \mathrm{M}$ for $\mathrm{TiO}_{2} / \beta-\mathrm{CD}$, $167 \times 10^{-7} \mathrm{M}$ for $\mathrm{ZnO} / \beta-\mathrm{CD}$; irradiation time $=120 \mathrm{~min}$; dose $=2 \mathrm{~g} / \mathrm{L}$

position of metal oxides. The zero charge point $\left(\mathrm{pH}_{\mathrm{ZPC}}\right)$ for $\mathrm{ZnO}$ is 8.8 and $\mathrm{TiO}_{2}$ is at 6.2. The extent of positive charges on the metal oxide surface decreases with increasing $\mathrm{pH}$ and reaches zero at $\mathrm{pH}_{\mathrm{ZPC}}$. Therefore, $\mathrm{pH}$ significantly affects the adsorption-desorption properties of the compounds on the surface of the catalysts. At $\mathrm{pH}>\mathrm{pH}_{\mathrm{ZPC}}, \mathrm{MO}^{-}$is the predominant species, whereas at $\mathrm{pH}<\mathrm{pH}_{\mathrm{ZPC}}, \mathrm{MOH}_{2}{ }^{+}$is the predominant species according to the Eqs. (2) and (3).

\section{Determination of $C O D$}

As the reduction of COD reflects the extent of photocatalytic decoloration of an organic species, the reduction of COD was studied as a function of $\mathrm{pH}$ using solar light irradiation.

Figure 12 presents the comparison between removal of $\mathrm{COD}$ of $\mathrm{RhB}$ with all the catalysts and shown that the COD decreases with increase in $\mathrm{pH}$ and initial $\mathrm{COD}$ values (460.6 mg $\mathrm{O}_{2} / \mathrm{L}$ for $\mathrm{TiO}_{2} ; 458.4 \mathrm{mg} \mathrm{O}_{2} / \mathrm{L}$ for $\mathrm{ZnO}$; $401.06 \mathrm{mg} \mathrm{O} / 2$ for $\mathrm{TiO}_{2} / \beta-\mathrm{CD}$ and $346.07 \mathrm{mg} \mathrm{O} / \mathrm{L}$ for $\mathrm{ZnO} / \beta-\mathrm{CD})$ were reduced after photocatalytic decoloration process. $\mathrm{COD}$ is significantly reduced with $\mathrm{ZnO} / \beta-\mathrm{CD}$ nanocomposites up to $18.09 \%$ than other catalysts (Dukkanci et al. 2010).

Role of $\beta-C D$ for the enhancement of photocatalytic activity of catalysts

A suitable mechanism for the photocatalytic decoloration of $\mathrm{RhB}$ with $\mathrm{MO} / \beta-\mathrm{CD}$ is proposed as given below (Eqs. 4-12) and also schematically represented 


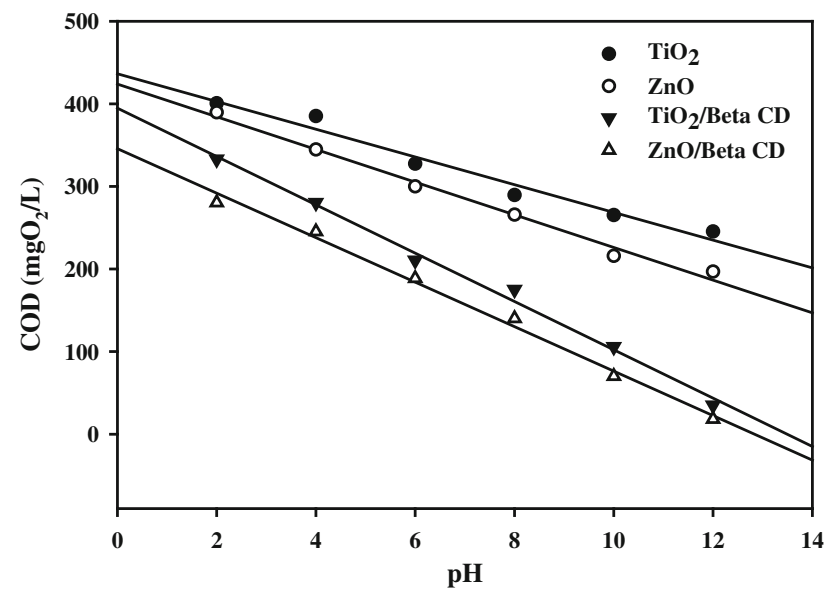

Fig. 12 Determination of COD for photocatalytic decoloration of $\mathrm{RhB}$ dye under solar light irradiation. $[\mathrm{RhB}]=4.1 \times 10^{-7} \mathrm{M}$ for $\mathrm{TiO}_{2}, 16.7 \times 10^{-7} \mathrm{M}$ for $\mathrm{ZnO}, 41.7 \times 10^{-7} \mathrm{M}$ for $\mathrm{TiO}_{2} / \beta-\mathrm{CD}$, $167 \times 10^{-7} \mathrm{M}$ for $\mathrm{ZnO} / \beta-\mathrm{CD}$; irradiation time $=120 \mathrm{~min}$; dose $=2 \mathrm{~g} / \mathrm{L}$

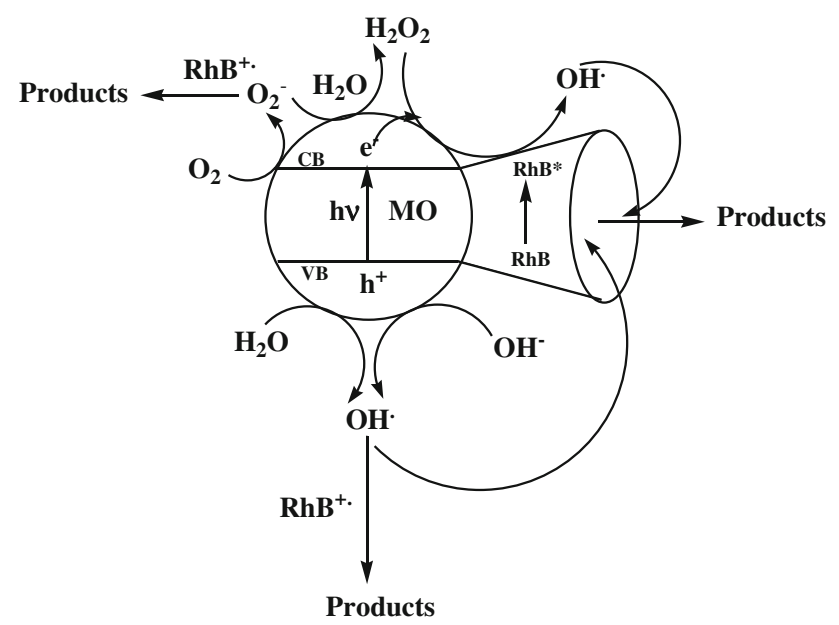

Scheme 1 Mechanism for the enhancement of photocatalytic decoloration of $\mathrm{RhB}$ dye with $\mathrm{MO} / \beta-\mathrm{CD}$ systems in Scheme 1. The RhB dye enters into the cavity of $\beta$ $\mathrm{CD}$, which is linked to the MO surface in the equilibrium stage. Since CDs have higher affinity for the MO surface than RhB, $\beta$-CD molecules could adsorb on the surface of the MO and occupy the reaction sites $\beta$-CD would capture holes on the active surface of $\mathrm{MO}$ resulting in the formation of stable $\mathrm{MO} / \beta-\mathrm{CD}$ complex (Eq. 4). Hence, the reaction between the reactants such as $\mathrm{RhB}$ and $\mathrm{MO} / \beta-\mathrm{CD}$ complex should be the key step in the photocatalytic degradation of $\mathrm{RhB}$ in MO suspension containing $\beta$-CD (Eq. 5) (Zhang et al. 2011). An electron is rapidly injected from the excited RhB to the conduction band (Hoffmann et al. 1995; Macwan et al. 2011; Zhang et al. 2009; Wang et al. 2006a). The enhancement of photocatalytic decoloration of $\mathrm{RhB}$ mainly resulted in the enhanced adsorption of $\mathrm{RhB}$ on $\mathrm{MO}$ surface and moderate inclusion depth of $\mathrm{RhB}$ in the $\beta$-CD cavity. Since $\beta$-CD can include the RhB into its cavity and adsorbed onto the surface of $\mathrm{MO}$, it could play a role as bridge or channel for $\mathrm{RhB}$ to get onto the MO surface and accumulate the higher concentrations, which makes the decoloration of RhB more easy and effective in the presence of hydroxyl radicals produced during photocatalytic decoloration processes. $\mathrm{MO} / \beta-\mathrm{CD}$ system apparently exhibited declined photoluminescence intensity compared with MO system which indicates that the electron/hole recombination has been suppressed in the $\mathrm{MO} / \beta-\mathrm{CD}$ nanocomposite systems. Therefore, the quantum efficiency of MO has been enhanced as the recombination of $\mathrm{e}_{\mathrm{CB}}^{-} / \mathrm{h}_{\mathrm{VB}}^{+}$is getting lowered, which resulted in the generation of more hydroxyl and superoxide radicals (Eqs. 6-9). Thus, the decoloration of the $\mathrm{RhB}$ and $\mathrm{RhB}^{+}$could be accelerated which leads to the formation of mineralized products (Eqs. 10-12) (Wang et al. 2006b; Lu et al. 2004).
Fig. 13 GC-MS spectra for the photocatalytic decoloration of $\mathrm{RhB}$ dye under solar light irradiation

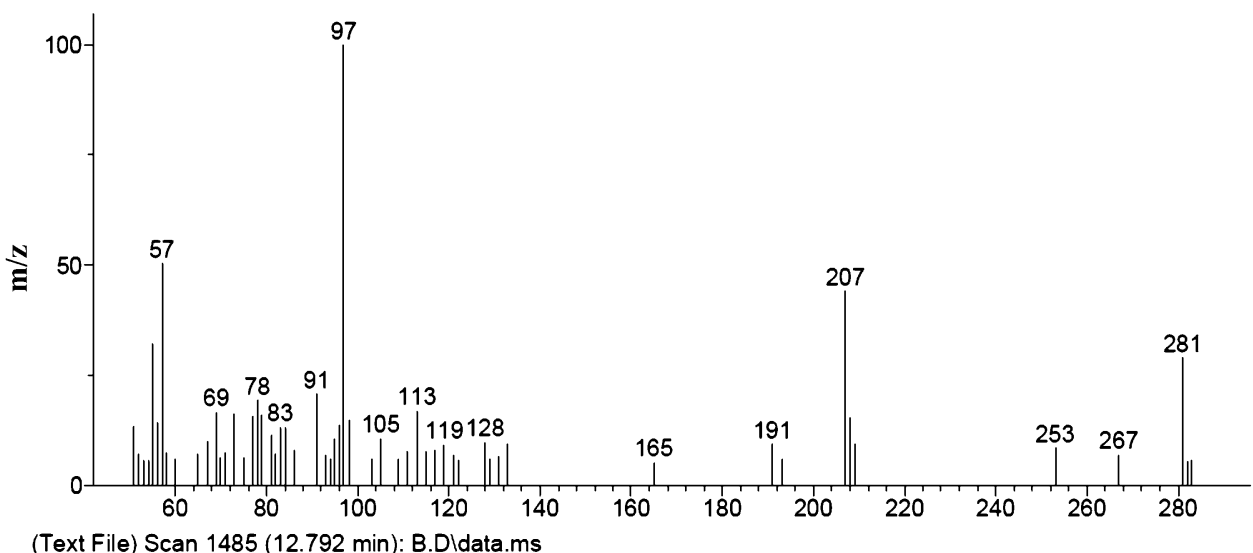

Retention time (min.) 
Scheme 2 Photocatalytic decoloration pathway for the photocatalytic decoloration of $\mathrm{RhB}$ dye under solar light irradiation

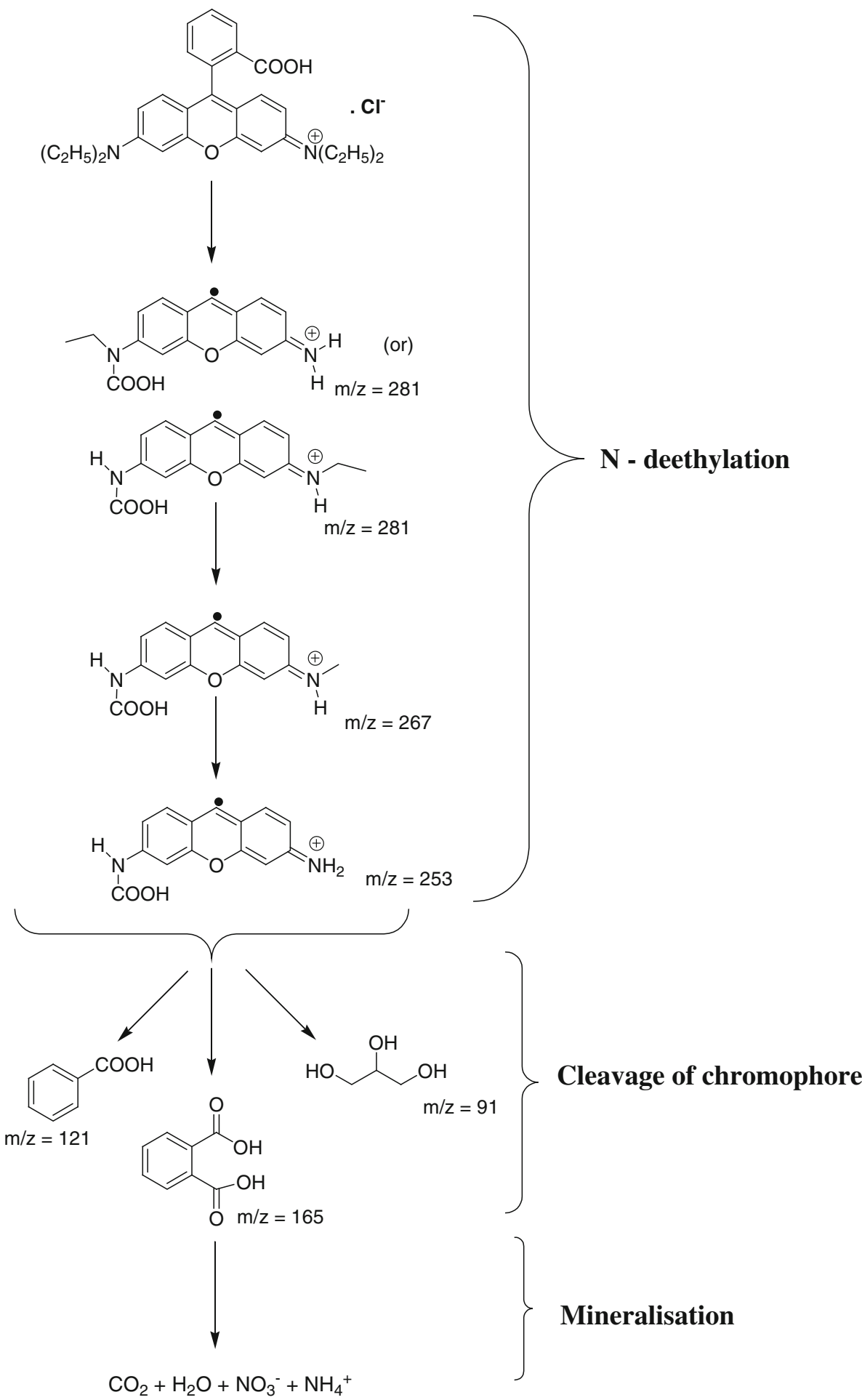

$$
\begin{aligned}
& \mathrm{MO}+\beta-\mathrm{CD} \rightarrow \mathrm{MO} / \beta-\mathrm{CD} \\
& \mathrm{RhB}+\mathrm{MO} / \beta-\mathrm{CD} \rightarrow \mathrm{MO} / \beta-\mathrm{CD}^{\bullet} \mathrm{RhB} \\
& \mathrm{MO} / \beta-\mathrm{CD}^{\bullet} \mathrm{RhB}+\mathrm{h} v \rightarrow \mathrm{MO} / \beta-\mathrm{CD}^{\bullet 1} \mathrm{RhB} *
\end{aligned}
$$$$
+\mathrm{MO} / \beta-\mathrm{CD}^{\bullet 3} \mathrm{RhB} *
$$

(4) $\mathrm{MO} / \beta-\mathrm{CD}^{\bullet 3} \mathrm{RhB} * \rightarrow(\mathrm{e}) \mathrm{MO} / \beta-\mathrm{CD}+\mathrm{RhB}^{\bullet+}$

(5) $\mathrm{MO} / \beta-\mathrm{CD}^{\bullet 1} \mathrm{RhB} *+\mathrm{O}_{2} \rightarrow \mathrm{MO} / \beta-\mathrm{CD}^{\bullet} \mathrm{RhB}+{ }^{1} \mathrm{O}_{2}$ 
$\mathrm{RhB}^{+\bullet} \rightarrow$ Products

$\mathrm{RhB}+{ }^{1} \mathrm{O}_{2} \rightarrow$ Products

$\mathrm{RhB}+{ }^{\bullet} \mathrm{O}_{2}^{-} \rightarrow$ Products

Photocatalytic pathway for the photodecoloration of $\mathrm{RhB}$ dye

Identification of possible intermediate products during the photocatalytic reaction is the best way to understand the photocatalytic decoloration reaction mechanism. To study the photocatalytic decoloration pathway of RhB dye under solar light irradiation as well as to identify the possible intermediate products during the photocatalytic decoloration, experiments were conducted with $\mathrm{ZnO} / \beta-\mathrm{CD}$ as a photocatalyst. GC-MS spectra of the irradiated aqueous solutions of $\mathrm{RhB}$ at different time intervals were observed with the time interval of $60 \mathrm{~min}$. Major intermediates during the photocatalytic decoloration process were proposed using $\mathrm{m} / \mathrm{z}(M-1)$ values of the GC-MS spectra (Fig. 13). Normally, RhB dye was found to be very stable under solar light irradiation in the absence of catalysts. Based on the results of GC-MS spectra, the fragmentation pathway and intermediates for the solar light-induced photocatalytic decoloration of $\mathrm{RhB}$ dye have been proposed and shown in Scheme 2. In photocatalytic decoloration of RhB dye three main steps are involved. They are (1) $\mathrm{N}$-deethylation, (2) cleavage of chromophore, (3) mineralization of dye. $\mathrm{N}$-deethylation followed by carboxylation lead to the formation of possible isomerized intermediates corresponding to the $\mathrm{m} / \mathrm{z}$ value of 281. After carboxylation, the formed intermediate degraded into possible intermediate with $\mathrm{m} / \mathrm{z}$ values of 267 and 253 and $\mathrm{m} / \mathrm{z}$ values 121,165 and 91 indicates that the RhB dye molecule is effectively oxidized by the catalysts into smaller molecules such as benzoic acid, phthalic acid and propane 1,2,3-triol. The formed oxidized products were then mineralized into $\mathrm{CO}_{2}, \mathrm{H}_{2} \mathrm{O}, \mathrm{NO}_{3}^{-}$and $\mathrm{NH}_{4}{ }^{+}$as reported in literatures (Kansal et al. 2007; Yu et al. 2009; Sun et al. 2009; He et al. 2009; Luan et al. 2011; Silva et al. 2011; Mehrdad et al. 2011; Li et al. 2007).

\section{Conclusions}

In summary, $\mathrm{ZnO} / \beta-\mathrm{CD}$ nanocomposite shows superior photocatalytic activities towards photocatalytic decoloration of RhB dye under solar light irradiation, which is due to the lower band gap energy of $\mathrm{ZnO}$ in $\mathrm{ZnO} / \beta$ $\mathrm{CD}$ system. Moreover, concentration of $\mathrm{RhB}$, irradiation time, dose of the catalysts used and $\mathrm{pH}$ of the reaction medium have significant effects on photocatalytic decoloration of $\mathrm{RhB}$ dye. $\beta$ - $\mathrm{CD}$ can include the $\mathrm{RhB}$ into its cavity and is adsorbed onto the surface of $\mathrm{MO}$, it could play a role as bridge or channel for $\mathrm{RhB}$ to get onto the MO surface and accumulate the higher concentrations, which makes the decoloration of $\mathrm{RhB}$ more easily and effectively in the presence of hydroxyl radicals produced during photocatalytic decoloration processes. The GC-MS spectral studies confirm the photocatalytic decoloration pathway of RhB dye which follows the steps such as $N$-deethylation, cleavage of chromophore and mineralization of dye. Based on the findings, $\mathrm{ZnO} / \beta-\mathrm{CD}$ nanocomposite can be used as an efficient photocatalyst for the photocatalytic decoloration of RhB dye.

Acknowledgments The authors thank the Management and the Principal of Ayya Nadar Janaki Ammal College, Sivakasi, India for providing necessary facilities. The University Grants Commission, New Delhi, is greatly acknowledged for providing financial support through UGC-Major Research Project [UGC-Ref. No. F. No. 38-22/ 2009 (SR) Dated: 19.12.2009]. Authors also acknowledged Bharadithasan University, Trichy for recording FE-SEM, ${ }^{1} \mathrm{H}$ NMR spectra and GC-MS analyses and Department of Earth Science, Pondicherry University, Pondicherry for recording PXRD spectrum.

Open Access This article is distributed under the terms of the Creative Commons Attribution License which permits any use, distribution, and reproduction in any medium, provided the original author(s) and the source are credited.

\section{References}

Alhakimi G, Studnicki LH, Al-Ghazali M (2003) Photocatalytic destruction of potassium hydrogen phthalate using $\mathrm{TiO}_{2}$ and sunlight: application for the treatment of industrial wastewater. J Photochem Photobiol A: Chem 154(2-3):219-228

Aliabadi M, Sagharigar T (2011) Photocatalytic removal of Rhodamine $\mathrm{B}$ from aqueous solutions using $\mathrm{TiO}_{2}$ nanocatalyst. J Appl Environ Biol Sci 1(12):620-626

Attarchi N, Montazer M, Toliyat $\mathrm{T}$ (2013) Ag/TiO $/ 3-\mathrm{CD}$ nano composite: preparation and photo catalytic properties for methylene blue degradation. Appl Catal A: Gen 467:107-116

Beltran-Heredia J, Sanchez-Martin J, Rodriguez-Sanchez MT (2011) Textile wastewater purification through natural coagulants. Appl Water Sci 1(1-2):25-33

Chen Y, Wang K, Lou L (2004) Photodegradation of dye pollutants on silica gel supported $\mathrm{TiO}_{2}$ particles under visible light irradiation. J Photochem Photobiol A: Chem 163(1-2):281-287

Damardji B, Khalaf H, Duclaux L, David B (2009) Preparation of $\mathrm{TiO}_{2}$-pillared montmorillonite as photocatalyst part II-photocatalytic degradation of a textile azo dye. Appl Clay Sci 45(1-2):98-104

Daneshvar N, Salari D, Khataee AR (2003a) Photocatalytic degradation of azo dye acid red 14 in water: investigation of the effect of operational parameters. J Photochem Photobiol A: Chem 157(1):111-116

Daneshvar N, Salari D, Khataee AR (2003b) Photocatalytic degradation of azo dye acid red 14 in water: investigation of the effect of operational parameters. J Photochem Photobiol A: Chem 157(1):111-116

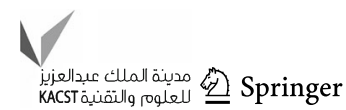


Dlamini LN, Krause RW, Kulkarni GU, Durbach SH (2011) Photodegradation of bromophenol blue with fluorinated $\mathrm{TiO}_{2}$ composite. Appl Water Sci 1(1-2):19-24

Dong B, Li Z, Li Z, Xu X, Song M, Zheng W, Wang C, Al-Deyab SS, El-Newehy M (2010) Highly efficient $\mathrm{LaCoO}_{3}$ nanofibers catalysts for photocatalytic degradation of Rhodamine B. J Am Cer Soc 93(11):3587-3590

Dukkanci M, Gunduz G, Yilmaz S, Prihodko RV (2010) Heterogeneous fenton-like degradation of Rhodamine $6 \mathrm{G}$ in water using CuFeZSM- 5 zeolite catalyst prepared by hydrothermal synthesis. J Hazard Mater 181(1-3):343-350

Grzechulska J, Morawski AW (2002) Photocatalytic decomposition of azo-dye acid black 1 in water over modified titanium dioxide. Appl Catal B: Environ 36(1):45-51

He Z, Sun C, Yang S, Ding Y, He H, Wang Z (2009) Photocatalytic degradation of Rhodamine $\mathrm{B}$ by $\mathrm{Bi}_{2} \mathrm{WO}_{6}$ with electron accepting agent under microwave irradiation: mechanism and pathway. J Hazard Mater 162(2-3):1477-1486

Hoffmann MR, Martin ST, Choi W, Bahnemann DW (1995) Environmental applications of semiconductor photocatalysis. Chem Rev 95(1):69-96

Jain R, Mathur M, Sikarwar S, Mittal A (2007) Removal of the hazardous dye Rhodamine B through photocatalytic and adsorption treatments. J Environ Manag 85(4):956-964

Kansal SK, Singh M, Sud D (2007) Studies on photodegradation of two commercial dyes in aqueous phase using different photocatalysts. J Hazard Mater 141(3):581-590

Kansal SK, Singh M, Sud D (2008) Studies on $\mathrm{TiO}_{2} / \mathrm{ZnO}$ photocatalyzed degradation of lignin. J Hazard Mater 153(1-2):412-417

Karunakaran C, Gomathisankar P, Manikandan G (2010) Preparation and characterization of antimicrobial $\mathrm{Ce}$-doped $\mathrm{ZnO}$ nanoparticles for photocatalytic detoxification of Cyanide. Mater Chem Phys 123(2-3):585-594

Kelesoglu S, Kes M, Sutcu L, Polat H (2012) Adsorption of methylene blue from aqueous solution on high lime fly ash: kinetic, equilibrium, and thermodynamic studies. J Disper Sci Technol 33(1):15-23

Kou T, Jin C, Zhang C, Sun J, Zhang Z (2012) Nanoporous core-shell $\mathrm{Cu} @ \mathrm{Cu}_{2} \mathrm{O}$ nanocomposites with superior photocatalytic properties towards the degradation of methyl orange. RSC Adv 2(33):12636-12643

Li J, Ma W, Lei P, Zhao J (2007) Detection of intermediates in the $\mathrm{TiO}_{2}$-assisted photodegradation of Rhodamine $\mathrm{B}$ under visible light irradiation. J Environ Sci 19(7):892-896

Lu P, Wu F, Deng N (2004) Enhancement of $\mathrm{TiO}_{2}$ photocatalytic redox ability by $\beta$-cyclodextrin in suspended solutions. Appl Catal B: Environ 53(2):87-93

Luan J, Li M, Ma K, Li Y, Zou Z (2011) Photocatalytic activity of novel $\mathrm{Y}_{2} \mathrm{InSbO}_{7}$ and $\mathrm{Y}_{2} \mathrm{GdSbO}_{7}$ nanocatalysts for degradation of environmental pollutant Rhodamine $\mathrm{B}$ under visible light irradiation. Chem Eng J 167(1):162-171

Macwan DP, Dave PN, Chaturvedi S (2011) A review on nano- $\mathrm{TiO}_{2}$ sol-gel type syntheses and its applications. J Mater Sci 46(11):3669-3686

Mehrdad A, Massoumi B, Hashemzadeh R (2011) Kinetic study of degradation of Rhodamine $\mathrm{B}$ in the presence of hydrogen peroxide and some metal oxide. Chem Eng J 168(3):1073-1078

Pitchaimuthu S, Rajalakshmi S, Kannan N, Velusamy P (2013) Enhanced photocatalytic activity of titanium dioxide by $\beta$ Cyclodextrin in decoloration of Acid Yellow 99 dye. Desalin Water Treat 52(16-18):3392-3402

Pitchumani K, Velusamy P, Srinivasan C (1994) Selectivity in sodium borohydride reduction of coumarin encapsulated in $\beta$-cyclodextrin. Tetrahedron 50(45):12979-12988
Rajalakshmi S, Pitchaimuthu S, Kannan N, Velusamy P (2013) Photocatalytic effect of $\beta$-cyclodextrin on semiconductors for the removal of Acid Violet dye under UV light irradiation. Desalin Water Treat 52(16-18):3432-3444

Rauf MA, Salman Ashraf S (2009) Fundamental principles and application of heterogeneous photocatalytic degradation of dyes in solution. Chem Eng J 151(1-3):10-18

Salomatova VA, Pozdnyakova IP, Yansholeb VV, Wu F, Grivin VP, Bazhin NM, Plyusnin VF (2014) Photodegradation of 4,4-bis(4hydroxyphenyl)valeric acid and its inclusion complex with $\beta$ cyclodextrin in aqueous solution. J Photochem Photobiol A: Chem 274:27-32

Santhi T, Prasad AL, Manonmani S (2011) A comparative study of microwave and chemically treated Acacia nilotica leaf as an eco friendly adsorbent for the removal of Rhodamine B dye from aqueous solution. Arab J Chem. doi:10.1016/j.arabjc.2010.11. 008

Serra-Gomez R, Tardajos G, Gonzalez-Benito J, Gonzalez-Gaitano G (2012) Rhodamine solid complexes as fluorescence probes to monitor the dispersion of cyclodextrins in polymeric nanocomposites. Dyes Pigm 94(3):427-436

Silva NU, Nunes TG, Saraiva MS, Shalamzari MS, Vaza PD, Monteiro OC, Nunes CD (2011) Photocatalytic degradation of rhodamine B using Mo heterogeneous catalysts under aerobic conditions. Appl Catal B: Environ 113-114:180-191

Sun M, Li D, Chen Y, Chen W, Li W, He Y, Fu X (2009) Synthesis and photocatalytic activity of calcium antimony oxide hydroxide for the degradation of dyes in water. J Phys Chem C 113(31):13825-13831

Velmurugan R, Swaminathan M (2011) An efficient nano structured $\mathrm{ZnO}$ for dye sensitized degradation of Reactive Red 120 dye under solar light. Sol Energy Mater Sol Cell 95(3):942-950

Velusamy P (1998) Study of thermal and photochemical reactions in cyclodextrin. Ph.D. thesis submitted to Madurai Kamaraj University, Madurai, p 50

Velusamy P, Pitchumani K, Srinivasan C (1996) Selectivity in bromination of aniline and $\mathrm{N}$-substituted anilines encapsulated in $\beta$-cyclodextrin. Tetrahedron 52(10):3487-3496

Velusamy P, Rajalakshmi S, Pitchaimuthu S, Kannan N (2011) Photo decoloration of organic dyes on $\beta$-cyclodextrin modified $\mathrm{ZnO}$. Indian J Environ Prot 31(10):801-809

Velusamy P, Rajalakshmi S, Pitchaimuthu S, Kannan N (2013) Photo decoloration of Brilliant Green dye using $\beta-\mathrm{CD}$ modified $\mathrm{TiO}_{2}$. Indian J Environ Protect 33(7):583-589

Velusamy P, Pitchaimuthu S, Rajalakshmi S, Kannan N (2014) Modification of the photocatalytic activity of $\mathrm{TiO}_{2}$ by $\beta$ cyclodextrin in decoloration of Ethyl Violet dye. J Adv Res 5(1):19-25

Wang G, Wu F, Zhang X, Luo M, Deng N (2006a) Enhanced $\mathrm{TiO}_{2}$ photocatalytic degradation of bisphenol $\mathrm{E}$ by $\beta$-cyclodextrin in suspended solutions. J Hazard Mater B 133(1-3):85-91

Wang G, Wu F, Zhang X, Luo M, Deng N (2006b) Enhanced $\mathrm{TiO}_{2}$ photocatalytic degradation of bisphenol $\mathrm{A}$ by $\beta$-cyclodextrin in suspended solutions. J Photochem Photobiol A: Chem 179(1-2):49-56

Wang H, Niu J, Long X, He Y (2008) Sonophotocatalytic degradation of Methyl Orange by nano-sized $\mathrm{Ag} / \mathrm{TiO}_{2}$ particles in aqueous solutions. Ultrason Sonochem 15(4):386-392

Wang J, Li J, Zhang L, Li C, Xie Y, Liu B, Xu R, Zhang X (2009a) Photocatalytic degradation of organic dyes by a high efficient $\mathrm{TiO}_{2}$-based catalysts under solar light irradiation. Catal Lett 130(3-4):551-557

Wang X, Wang J, Guo P, Guo W, Wang C (2009b) Degradation of Rhodamine $\mathrm{B}$ in aqueous solution by using swirling jet-induced 
cavitation combined with $\mathrm{H}_{2} \mathrm{O}_{2}$. J Hazard Mater 169(1-3):486-491

Xin F, Zhang H, An W, Sun L, Hao A, Li Y (2012) Vesicles prepared from inclusion complexes between cyclodextrins and ethyl benzoate. J Disper Sci Technol 33(1):1-4

Yang Z, Zhang X, Cui J (2014) Self-assembly of bioinspired catecholic cyclodextrin $\mathrm{TiO}_{2}$ heterosupramolecule with high adsorption capacity and efficient visible-light photoactivity. Appl Catal B: Environ 148-149:243-249

Yu K, Yang S, He H, Sun C, Gu C, Ju Y (2009) Visible light-driven photocatalytic degradation of Rhodamine $\mathrm{B}$ over $\mathrm{NaBiO}_{3}$ : pathways and mechanism. J Phys Chem A 113(37):10024-10032

Zhang X, Wu F, Wang B, Deng N, Luo M (2007) Research of inclusion complexation of $4,4^{\prime}$-thiodiphenol effected by $\beta$ - cyclodextrin in aqueous solutions and the effect on photodegradation. Wuhan Univ J Nat Sci 12(3):535-540

Zhang X, Wu F, Wang Z, Guo Y, Deng N (2009) Photocatalytic degradation of 4, 4-biphenol in $\mathrm{TiO}_{2}$ suspension in the presence of cyclodextrins: a trinity integrated mechanism. J Mol Catal A: Chem 301(1-2):134-139

Zhang X, Wu F, Deng N (2011) Efficient photodegradation of dyes using light-induced self-assembly $\mathrm{TiO}_{2} / \beta$-cyclodextrin hybrid nanoparticles under visible light irradiation. J Hazard Mater 185(1):117-123 